\title{
Nutrient-specific food selection buffers the effect of nutritional imbalance in the mealworm beetle, Tenebrio molitor (Coleoptera: Tenebrionidae)
}

\author{
Myung Suk RHO and Kwang Pum LEE* \\ Department of Agricultural Biotechnology, Seoul National University, Seoul 151-921, Republic of Korea; \\ e-mails: kwanglee@snu.ac.kr; goldsky2000@snu.ac.kr
}

Key words. Coleoptera, Tenebrionidae, Tenebrio molitor, mealworm, carbohydrate, compensation, feeding behaviour, foraging, macronutrient, nutrient balancing, protein

\begin{abstract}
Ingesting nutritionally imbalanced food can cause a significant reduction in fitness in insects. Insects can avoid the negative consequences of nutritional imbalances by selectively foraging for nutritionally complementary foods. We investigated the ability of the omnivorous beetle, Tenebrio molitor (Coleoptera: Tenebrionidae), to redress nutritional imbalances by selecting complementary foods. Beetles were fed one of three synthetic diets that varied in their protein: carbohydrate balance (p0:c42, p21:c21 or p42:c0) for 16 days and then allowed to select between two nutritionally imbalanced but complementary diets (p0:c42 vs. p42:c0) for 18 days. During the initial period, beetle survival was high on all three experimental diets, but their body composition was considerably skewed as a result of eating nutritionally imbalanced diets. Over the first 6 days of food choice (days 16-22), beetles previously fed a protein-rich, carbohydrate-deficient diet (p42:c0) preferred carbohydrate to protein, whereas those previously fed a carbohydrate-rich, protein-deficient diet ( $\mathrm{p} 0: \mathrm{c} 42)$ strongly preferred the protein-rich diet. When the food choice period continued for longer than 6 days, the selection of diets by previously carbohydrate-deprived beetles (p42:c0) was similar to that of the control beetles previously fed an optimal food (p21:c21). However, beetles that were previously fed on the protein-deficient diet (p0:c42) selected protein and carbohydrate equally throughout the remaining period of food choice and the cumulative protein-carbohydrate intake of these protein-deprived beetles was similar to that of those fed the optimal diet (p21:c21). At the end of the experiment, the body composition of all beetles was similar, indicating that the effects of nutritional imbalance on body composition were buffered by the subsequent selection of complementary foods. Our results demonstrate that $T$. molitor beetles are capable of redressing nutritional imbalances and indicate that the way in which the nutritional balance of beetles is restored depends on the nutrient that is initially deficient in their food.
\end{abstract}

\section{INTRODUCTION}

Insects can maximize their Darwinian fitness when they acquire an optimal amount and blend of nutrients (Simpson et al., 2004; Lee et al., 2008; Jensen et al., 2012; Roeder \& Behmer, 2014). Protein and carbohydrate are the two major macronutrients that are extensively used to investigate the effects of macronutrient balance on various aspects of physiology, behaviour and life-history performance in insects (Behmer, 2009; Simpson \& Raubenheimer, 2012). When protein and carbohydrate are ingested in imbalanced quantities and ratios, insects suffer significant performance costs arising from ingesting not only too little of one nutrient (Mattson, 1980; White, 1993), but also too much of a nutrient that occurs in excess of their requirements (Simpson et al., 2004; Raubenheimer et al., 2005; Boersma \& Elser, 2006; Zehnder \& Hunter, 2009). For example, eating a diet containing excess protein relative to carbohydrate shortens lifespan in many insects (Lee et al., 2008, 2013; Fanson et al., 2012; Dussutour \& Simpson, 2012).

The detrimental effects of ingesting nutritionally imbalanced food can be ameliorated by insects using a variety of post-ingestive mechanisms (Zanotto et al., 1994, 1997; Raubenheimer \& Bassil, 2007; Clissold et al., 2010), but probably the most effective way to correct nutritional im- balances is to forage for nutritionally complementary foods (Waldbauer \& Friedman, 1991; Behmer, 2009; Simpson \& Raubenheimer, 2012). Insects have a well-developed capacity to assess their current nutritional state and adjust their food preferences in order to counterbalance the nutritional imbalances accrued over a wide range of timescales (Simpson et al., 1988, 1990, 1991; Simmonds et al., 1992; Mayntz et al., 2005; Raubenheimer \& Jones, 2006; Lee et al., 2012). The accuracy and efficiency with which insects restore their nutritional state are likely to depend on the extent and nature of the nutritional imbalance faced by insects, but little empirical work has been done to test this possibility in insects (but see Raubenheimer \& Jones, 2006; Lee et al., 2012).

In the present study, we investigate how protein : carbohydrate nutritional imbalances influence the pattern of complementary food selection in the mealworm beetle, Tenebrio molitor L. (Coleoptera: Tenebrionidae). To accomplish this, we experimentally manipulated the nutritional state of T. molitor beetles by feeding them for 16 days on one of three foods that differed in terms of their protein and carbohydrate content and then determining the patterns in their selection of different nutritionally complementary diets over the next 18 days. During the pretreatment period, beetles were fed one of the following

\footnotetext{
* Corresponding author.
} 
synthetic diets with identical caloric contents: (1) proteinrich, carbohydrate-deficient diet, (2) equal protein : carbohydrate balanced diet or (3) carbohydrate-rich, proteindeficient diet. Recent work has shown that both male and female beetles of $T$. molitor are capable of regulating their protein and carbohydrate intake independently, resulting in an intake ratio of protein: carbohydrate close to $1: 1$ (Rho \& Lee, 2014). This lead us to assume that a diet with an equal protein : carbohydrate $(1: 1)$ ratio is the optimal one for T. molitor beetles while the others are nutritionally imbalanced with one nutrient in excess and an insufficient quantity of the other. We hypothesized that beetles that were initially fed a diet devoid of a specific nutrient (protein or carbohydrate) would show a preference for a diet rich in the deficient nutrient. We also predicted that beetles would rely exclusively on controlling their food intake to compensate for protein-deficiency because nitrogen is only obtained by eating protein. When compensating for carbohydrate-deficiency, beetles are expected to be less reliant on their food intake because protein can be metabolized into carbohydrate by the process of gluconeogenesis (Thompson \& Redak, 2000). To test these predictions, we examined the food preference patterns of beetles previously fed diets differing in the protein: carbohydrate balance. We also compared the body composition of beetles that were allowed to select between the diets with that of those that were fed only one of three diets in order to determine whether the nutritional balance of their bodies recovered as a result of being able to select a particular diet.

\section{MATERIAL AND METHODS}

\section{Experimental foods}

Dry, granular, chemically-defined synthetic diets were prepared based on the established protocol outlined by Simpson \& Abisgold (1985). In total, we made three diets differing in protein (p) and digestible carbohydrate (c) content: $0 \%$ protein with $42 \%$ digestible carbohydrate (p0:c42), p21:c21 and p42:c0 (\% dry mass). The total concentration of protein plus carbohydrate was fixed at $42 \%$ for all three diets. Since protein and carbohydrate are similar in caloric density (4 calories per gram), all three foods used in this study are near isocaloric. The protein component of all diets was a $3: 1: 1$ mixture of casein, peptone and albumen, and sucrose was the digestible carbohydrate. All diets contained a fixed content of Wesson's salt $(2.4 \%)$, cholesterol $(0.5 \%)$, linoleic acid $(0.5 \%)$, ascorbic acid $(0.3 \%)$, a vitamin mix $(0.2 \%)$ and indigestible cellulose $(54 \%)$.

\section{Experimental procedures}

T. molitor were obtained from a stock culture maintained at Seoul National University. During the larval stages, insects were kept in groups of 300-400 individuals per plastic container (400 $\left.\times 180 \times 80 \mathrm{~cm}^{3}, \mathrm{~L} \times \mathrm{W} \times \mathrm{H}\right)$ where they had access to an ad libitum supply of wheat bran and water (water-filled plastic test tubes plugged with cotton wool) until pupation. Pupae were collected, sexed and allowed to complete their pupal development following the procedure described in Rho \& Lee (2014).

On the first day of the experiment (day 0), a total of 120 newly emerged adults (60 males and 60 females) were weighed to the nearest $0.1 \mathrm{mg}$ using a microbalance (Ohaus Co., Parsippany, NJ, USA), placed alone in experimental arenas (Petri dish diameter $90 \mathrm{~mm}$ ) and then randomly divided into three experimental groups. Over the first 16 days posteclosion (pretreatment period: days $0-16$ ), beetles in each group were supplied with one of the three diets differing in protein: carbohydrate balance ( $\mathrm{p} 0: \mathrm{c} 42$, $\mathrm{p} 21: \mathrm{c} 21$ and $\mathrm{p} 42: \mathrm{c} 0)$. After experiencing this pretreatment, beetles were then provided with two dishes of nutritionally imbalanced but complementary diets ( $\mathrm{p} 0: \mathrm{c} 42$ vs. $\mathrm{p} 42: \mathrm{c} 0$ ) for 18 days (choice period: days16-34). The upturned lids of $1.5 \mathrm{~mL}$ Eppendorf tubes (diameter $9 \mathrm{~mm}$, depth $5 \mathrm{~mm}$ ) were used as dishes for the dry, granular synthetic diet for the insects during the experiment. Before presenting them to insects, these dishes were filled with food, dried at $40^{\circ} \mathrm{C}$ for $24 \mathrm{~h}$ and weighed to the nearest $0.1 \mathrm{mg}$. Food and water (a water-filled $1.5 \mathrm{~mL}$ Eppendorf tube each capped with cotton wool) were replaced every other day. To minimize any measurement error in food consumption, each dish was placed in a small Petri dish (diameter $40 \mathrm{~mm}$ ) and any food spilled from the dish was put back in the dish before it was removed. Removed dishes containing uneaten food were dried to constant mass and weighed. Food consumption over each 2-day period was calculated as the difference between the dry mass of a dish initially given to insects and that of the same dish removed after two days of feeding. Food preference index was calculated for each beetle using the following formula:

\section{Preference index $=\frac{P-C}{P+C}$}

where $P$ and $C$ were the quantities of the p42:c0 and p0:c42 diets consumed, respectively. A positive value of this index thus indicates a preference for the $\mathrm{p} 42: \mathrm{c} 0$ diet and a negative value a preference for the $\mathrm{p} 0: \mathrm{c} 42$ diet. A value of zero indicates no preference. Protein and carbohydrate consumption were calculated as the product of food consumption and the concentration of each nutrient in the food. At the end of the experiment (day 34), beetles were frozen at $-80^{\circ} \mathrm{C}$ and dried to constant weight at $50^{\circ} \mathrm{C}$ for $72 \mathrm{~h}$. Dried carcasses were then weighed and lipid-extracted using three successive, $24 \mathrm{~h}$ chloroform washes (Simpson, 1982). Lipid-extracted carcasses were re-dried and then re-weighed, with total extractable lipid content being calculated as the difference between the pre- and post-extraction dry mass. The proteineous body tissue of lean carcasses was digested and removed by soaking them in $0.35 \mathrm{M}$ sodium hydroxide $(\mathrm{NaOH})$ solution for three days at $33^{\circ} \mathrm{C}$ before being re-dried and re-weighed (Marden, 1987). Crude protein content was estimated by taking the difference between the dry mass of the sample before and after soaking them in sodium hydroxide. To measure the body composition of beetles at the end of the pretreatment period (day 16), we used another 120 newly eclosed adults (60 males and 60 females) that received the same pretreatment foods for 16 days, after which they were killed and subjected to body chemical composition analysis following the same protocol outline above. An earlier study indicated that there were no significant differences in dry body weight and body composition (protein and lipid content) between male and female beetles at adult emergence (day 0 ) (Rho \& Lee, 2014). Throughout the whole experiment, all insects were kept in an incubator at $25^{\circ} \mathrm{C}$ under a $12 \mathrm{~L}: 12 \mathrm{D}$ photoregime.

\section{Data analysis}

Both univariate and multivariate analysis of variance (ANOVA or MANOVA) were used to test the significance of the effects of pretreatment diet and sex on nutrient consumption and body composition. For the multivariate analysis, we used the Pillai's trace statistic because it is robust to the violations of assumptions (Scheiner, 1993). Patterns of food preference in beetles that were offered two diets (p40:c0 vs. p0:c42) over three 6-day intervals were analyzed using a repeated measures ANOVA with sex and pretreatment diet as between-subject effects, and time (6-day in- 
tervals) and its interactions with sex and diet as within-subject effects. One-sample $t$-test was used to determine whether diet preference indices were significantly different from zero. Before the analyses, the data were checked for normality and heteroscedasticity using Kolmogorov-Smirnov and Bartlett's test, respectively. All data conformed to the assumptions of parametric tests. All statistical analyses were performed using SAS version 9.12 (SAS Institute, Cary, NC, USA).

\section{RESULTS}

\section{Performance}

All experimental beetles survived the experiment. However, 18 insects [four (males), four (one male and three females) and ten (four males and six females) individuals in the pretreatment groups p0:c42, p21:c21 and p42:c0, respectively] ate substantially less diet than the others and were not included in the analyses. There was no significant difference in the number of these beetles among the six sex $\times$ diet combinations (Analysis of deviance: $\chi^{2}=1.61$, $\mathrm{df}=1, P=0.204)$. The dry body weight of beetles at the end of the experiment (day 34) was neither affected by experimental diet (ANOVA: $F_{2,96}=0.08, P=0.925$ ) nor by $\operatorname{sex}\left(F_{1,96}=0.14, P=0.708\right)$. Nor was there any interaction between diet and sex for body weight $\left(F_{2,96}=1.19, P=\right.$ 0.307).

\section{Food preference}

Results from a repeated measures ANOVA indicated that the pattern in food preference was significantly affected by the $\mathrm{P}: \mathrm{C}$ ratio of pretreatment diet, sex and time (three 6-day intervals; Table 1). A significant time $\times$ diet interaction indicated that the effect of the pretreatment diet on food preference changed significantly over time, but time $\times$ sex and time $\times \operatorname{sex} \times$ diet interactions were not significant (Table 1). When a repeated measures ANOVA with the pretreatment diet as the only between-subject effect was conducted separately for male and female beetles, time $\times$ diet interaction was significant for both male $\left(F_{4,104}\right.$ $=9.35, P<0.001)$ and female beetles $\left(F_{4,88}=6.07, P<\right.$ 0.001 ). Over the first 6 days of food choice (days 16-22), the pattern in diet preferences differed significantly among the three pretreatment groups (ANOVA, male: $F_{2,52}=$ 54.84, $P<0.001$; female: $F_{2.44}=23.78, P<0.001$; Fig. 1$)$. During this period, both male and female beetles initially fed the carbohydrate-rich, protein-deficient diet (p0:c42) strongly preferred the protein-rich, carbohydrate-deficient diet (p42:c0) (positive signs; one-sample $t$ tests, male: $t_{19}$ $=7.80, P<0.001$; female: $t_{15}=2.29, P=0.01$ ), while the pattern was reversed for those initially fed the protein-rich, carbohydrate-deficient diet (p42:c0) (negative signs; male: $t_{15}=-7.96, P<0.001$; female: $t_{13}=-9.41, P<0.001$; Fig. 1$)$. Beetle initially fed the equally balanced diet (p21:c21) preferred the carbohydrate-rich diet ( $\mathrm{p} 0: \mathrm{c} 42)$ to the proteinrich diet (p42:c0) (negative signs; male: $t_{18}=-2.62, P=$ 0.017; female: $t_{16}=-2.84, P=0.012$ ) over the first 6 days (days 16-22; Fig. 1), but the extent to which the former was preferred was less pronounced than for those that were initially fed the protein-rich, carbohydrate-deficient diet (p42:c0). Over the next two 6-day periods (days 22-28 and

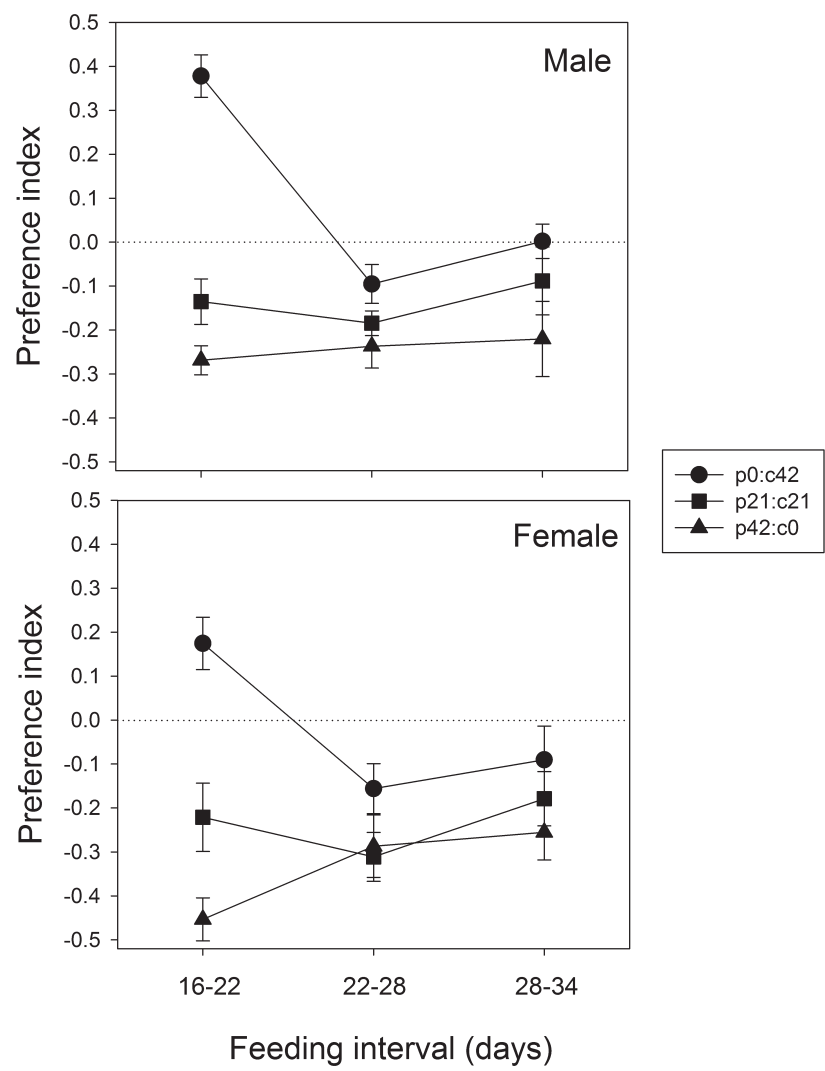

Fig. 1. Trends recorded in the food preference indices of male and female Tenebrio molitor beetles allowed to select between two nutritionally complementary diets (p42:c0 vs. p0:c42) during three successive 6-day periods (days 16-22, 22-28 and 28-34) after initially being fed one of three diets (p0:c42, p21:c21 or $\mathrm{p} 42: \mathrm{c} 0)$ for 16 days. Positive and negative indices indicate preferences for the $\mathrm{p} 42: \mathrm{c} 0$ and $\mathrm{p} 0: \mathrm{c} 42$ diet, respectively. Values are means \pm 1 S.E.M.

28-34), the initial differences in the preferences among the three experimental groups were greatly reduced and eventually they became statistically indistinguishable from one another (days 28-34; ANOVA, male: $F_{2,52}=3.16, P=$ 0.051; female: $F_{2,44}=1.22, P=0.305$; Fig. 1). Preference

TABLE 1. Results of repeated measures ANOVA of the food preference indices of Tenebrio molitor beetles (male and female; sex) that were given a choice between two nutritionally complementary diets (p42:c0 vs. p0:c42) over three successive 6-day periods (days 16-22, 22-28 and 28-34; time) after initially being fed on one of three diets (p0:c42, p21:c21 or p42:c0; diet) for 16 days.

\begin{tabular}{lrrrr}
\hline Source & df & Mean Square & $F$ & \multicolumn{1}{c}{$P$} \\
\hline Between subject effects & & & & \\
Sex & 1 & 0.78662 & 9.74 & 0.002 \\
Diet & 2 & 2.96271 & 36.69 & $<0.001$ \\
Sex $\times$ Diet & 2 & 0.00652 & 0.08 & 0.923 \\
Error & 96 & 0.08076 & & \\
\hline Within subject effects & & & & \\
Time & 2 & 0.44510 & 9.66 & $<0.001$ \\
Time $\times$ Sex & 2 & 0.06897 & 1.50 & 0.227 \\
Time $\times$ Diet & 4 & 0.66104 & 14.35 & $<0.001$ \\
Time $\times$ Sex $\times$ Diet & 4 & 0.03229 & 0.70 & 0.581 \\
Error & 192 & 0.04605 & & \\
\hline
\end{tabular}



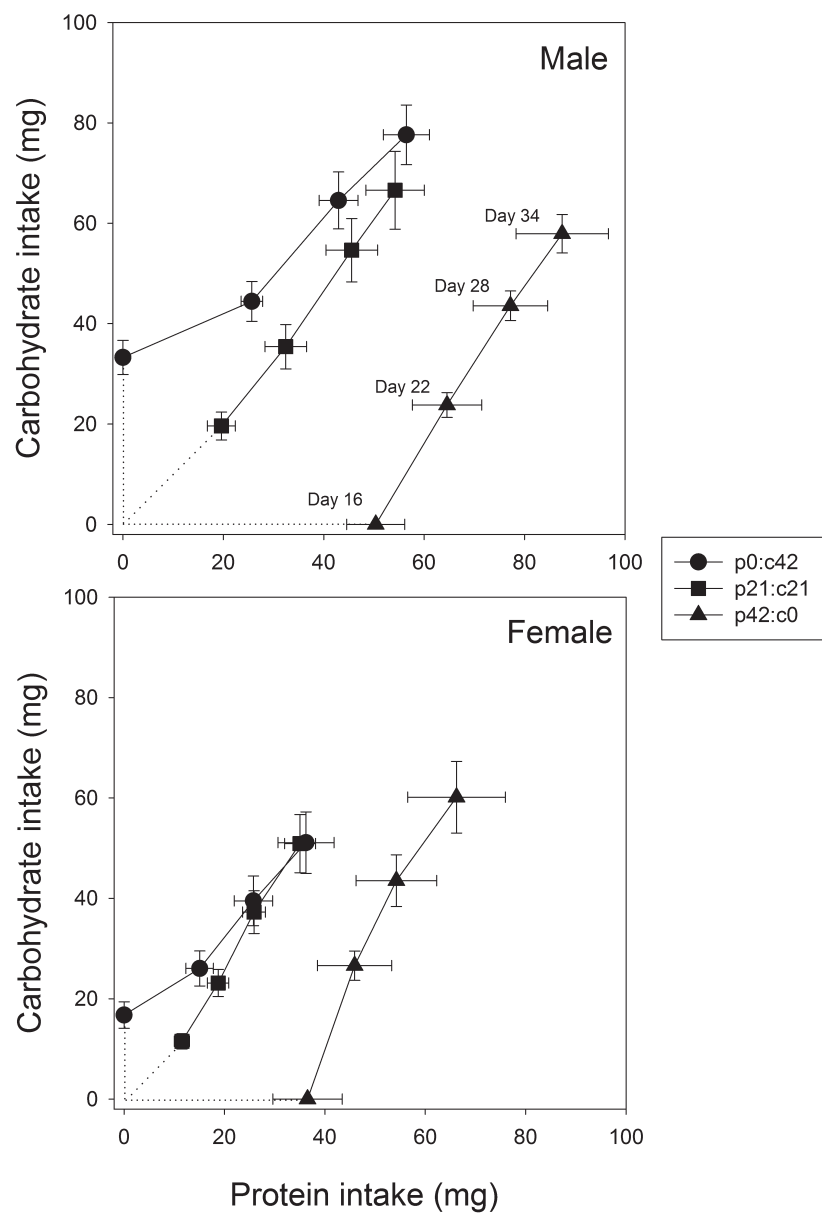

Fig. 2. Cumulative amount of protein and carbohydrate eaten by male and female Tenebrio molitor beetles allowed to select between two nutritionally complementary diets (p42:c0 vs. p0:c42) during three successive 6-day periods (days 16-22, 22-28 and 28-34) after initially being fed one of three diets (p0:c42, p21:c21 or $\mathrm{p} 42: \mathrm{c} 0$ ) for 16 days. Dotted and solid lines radiating from the origin represent the trajectories of cumulative protein-carbohydrate intake during the first 16 days of the no-choice feeding (days 0-16) and the three, 6-day periods (days 16-22, 22-28 and 28-34) of choice feeding, respectively. For each diet, four symbols starting from left to right indicate the cumulative nutrient intake on days 16, 22, 28 and 34, respectively. Values are means \pm 1 S.E.M. indices recorded in these two 6-day periods were significantly negative for both male and female beetles initially fed the protein-rich, carbohydrate-deficient diet (p42:c0) and for female beetles initially fed the equally balanced diet (p21:c21), indicating a preference for the carbohydraterich, protein-deficient diet (p0:c42; all $P$ values generated from one-sample $t$ tests being lower than 0.014). For both male and female beetles initially fed the carbohydrate-rich, protein-deficient diet (p0:c42), however, preference indices were not significantly different from zero (male: $t_{19}=$ $0.05, P=0.959$; female: $t_{15}=-1.18, P=0.258$ ), indicating that they did not show a preference for a specific food.

\section{Macronutrient consumption}

The cumulative patterns in protein-carbohydrate consumption are described separately for male and female beetles in Fig. 2 over the entire experimental period (days 0-34), including those for both the no-choice (days 0-16) and choice feeding (days 16-34) trials. During the nochoice period (days $0-16$ ), males consumed significantly more nutrients than females on all three diets (ANOVA: $F_{1,96}=16.16, P<0.001$; Fig. 2). For both sexes, the total amount of macronutrients consumed over the no-choice period increased with increase in the $\mathrm{P}: \mathrm{C}$ ratio of the nochoice diet $\left(F_{2,96}=7.53, P<0.001\right.$; Fig. 2$)$. There was no significant diet $\times$ sex interaction $\left(F_{2,96}=0.05, P=0.955\right)$, indicating that both sexes followed a similar pattern of macronutrient consumption when each was provided with only one of the three diets. Results of a MANOVA and its post-hoc contrasts confirmed that the bivariate pattern of cumulative protein-carbohydrate intake over the nochoice period (days 0-16) differed significantly among the three experimental groups for both sexes (Table 2). When the trajectories of cumulative protein-carbohydrate intake moving through nutrient space over the food choice period (days 16-34) were compared among the three groups (Fig. $2)$, the intake trajectory of beetles that were initially fed the protein-rich, carbohydrate-deficient diet (42:c0) almost paralleled that of those that were initially fed the equally balanced diet (p21:c21) in both sexes. However, we also found that the intake trajectory of beetles initially fed the

TABLE 2. Results recorded for the MANOVAs of the protein-carbohydrate intake by (A) male and (B) female Tenebrio molitor beetles during the no-choice feeding period (days 0-16) and the entire experimental period (days 0-34). Results of multivariate contrasts between two diet groups (p0:c42 vs. p21:c21, p0:c42 vs. p42:c0 and p21:c21 vs. p42:c0) are reported below the MANOVA result for each sex.

\begin{tabular}{|c|c|c|c|c|c|c|c|c|}
\hline \multirow{2}{*}{ Source } & \multicolumn{4}{|c|}{ Days $0-16$} & \multicolumn{4}{|c|}{ Days 0-34 } \\
\hline & df & Pillai's trace & $F$ & $P$ & df & Pillai's trace & $F$ & $P$ \\
\hline \multicolumn{9}{|l|}{ Male } \\
\hline Diet & 4,104 & 0.83491 & 18.63 & $<0.001$ & 4,104 & 0.58702 & 10.80 & $<0.001$ \\
\hline \multicolumn{9}{|l|}{ Contrasts } \\
\hline p0:c42 vs. p21:c21 & 2,51 & 0.46659 & 22.31 & $<0.001$ & 2,51 & 0.05114 & 1.37 & 0.262 \\
\hline p0:c42 vs. p42:c0 & 2,51 & 0.83409 & 128.19 & $<0.001$ & 2,51 & 0.54272 & 30.26 & $<0.001$ \\
\hline p21:c21 vs. p42:c0 & 2,51 & 0.64009 & 45.35 & $<0.001$ & 2,51 & 0.44936 & 20.81 & $<0.001$ \\
\hline \multicolumn{9}{|l|}{ Female } \\
\hline Diet & 4,88 & 0.70413 & 11.95 & $<0.001$ & 4,88 & 0.32793 & 4.31 & 0.003 \\
\hline \multicolumn{9}{|l|}{ Contrasts } \\
\hline p0:c42 vs. p21:c21 & 2,43 & 0.20051 & 5.39 & 0.008 & 2,43 & 0.00075 & 0.02 & 0.984 \\
\hline p0:c42 vs. p42:c0 & 2,43 & 0.69715 & 49.49 & $<0.001$ & 2,43 & 0.26148 & 7.61 & 0.002 \\
\hline p21:c21 vs. p42:c0 & 2,43 & 0.52682 & 23.94 & $<0.001$ & 2,43 & 0.28385 & 8.52 & $<0.001$ \\
\hline
\end{tabular}



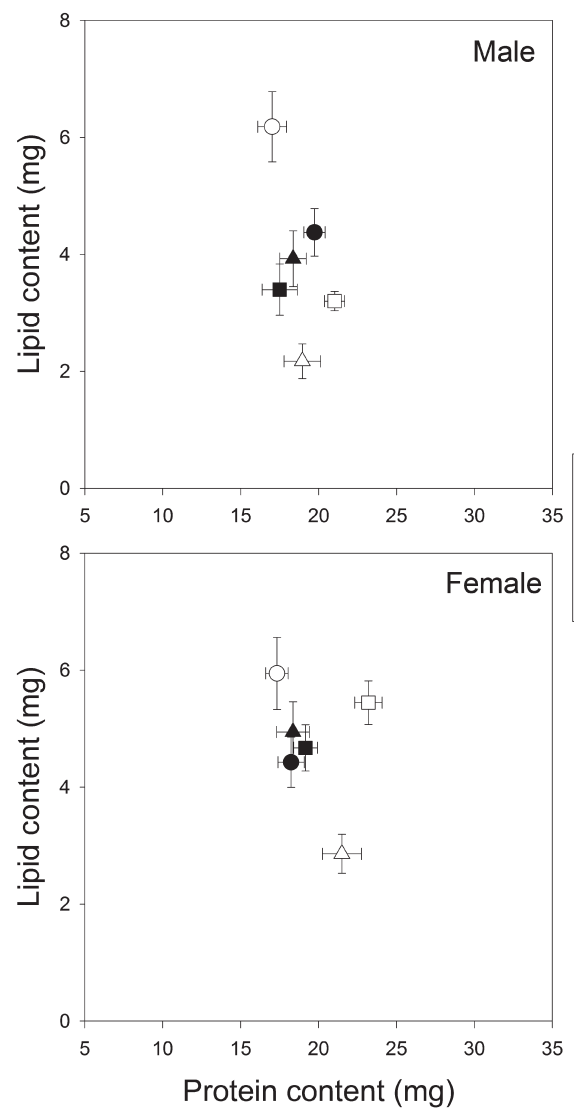

Fig. 3. The amount of body lipid and protein content of Tenebrio molitor beetles in the three pretreatment groups ( $\mathrm{p} 0: \mathrm{c} 42$, $\mathrm{p} 21: \mathrm{c} 21$ or $\mathrm{p} 42: \mathrm{c} 0$ ) measured at the end of the no-choice (days 0-16; open symbols) and choice feeding periods (days 0-34; closed symbols). Values are means \pm 1 S.E.M.

carbohydrate-rich, protein-deficient diet (p0:c42) had a much shallower slope than the trajectories of those fed the other two diets (p21:c21 and p42:c0 pretreatment groups) especially during the first 6 days of food choice (days 1622; Fig. 2). For both sexes, results of the MANOVA contrasts revealed that the cumulative protein-carbohydrate intake point of beetles initially fed the protein-deficient diet (p0:c42) and the equally balanced diet (p21:c21) converged and became statistically indistinguishable when measured at the end of the food choice experiment (day 34; Table 2; Fig. 2). Cumulative macronutrient intake of beetles initially fed on the protein-rich, carbohydrate-deficient diet (p42:c0) differed significantly from that of those initially fed on the other diets (Table 2; Fig. 2). While the cumulative protein intake of both male and female beetles on day 34 posteclosion differed significantly among the three experimental groups (ANOVA, male: $F_{2.52}=7.70, P=0.001$; female: $F_{2,44}=7.44, P=0.001$ ), their final carbohydrate intake was statistically indistinguishable (male: $F_{2.52}=2.44$, $P=0.097$; female: $F_{2,44}=0.66, P=0.521$ ).

\section{Body composition}

The bivariate pattern of body protein and lipid content at the end of the initial no-choice period (day 16) differed significantly depending on the $\mathrm{P}: \mathrm{C}$ ratio of the diet they fed on (MANOVA, male: Pillai's trace $=0.78971, F_{4,102}=$
16.64, $P<0.001$; female: Pillai's trace $=0.75618, F_{4,106}=$ 16.11, $P<0.001$; Fig. 3). Body lipid content of beetles on day 16 posteclosion increased significantly with the carbohydrate content of the food they fed on (ANOVA, male: $F_{2,51}=24.24, P<0.001$; female: $\left.F_{2,53}=13.90, P<0.001\right)$. Body protein content on day 16 posteclosion also varied significantly among the three pretreatment groups (male: $F_{2,51}=5.62, P=0.006$; female: $\left.F_{2,53}=8.84, P<0.001\right)$. When the body composition was measured at the end of the food choice period (day 34), the bivariate pattern of body nutrient composition of the three experimental groups converged and became statistically indistinguishable from one another (MANOVA, male: Pillai's trace $=0.06691, F_{4,104}$ $=0.90, P=0.467$; female: Pillai's trace $=0.04491, F_{4,88}=$ $0.51, P=0.732$; Fig. 3$)$. The protein contents of the two sexes on day 34 posteclosion were similar $\left(F_{1,96}=0.24, P\right.$ $=0.625)$, but females had a significantly greater body lipid content than males (ANOVA: $F_{1,96}=5.36, P=0.023$ ), causing the bivariate body composition to be significantly different between the two sexes (MANOVA: Pillai's trace $\left.=0.07182, F_{2.95}=3.68, P=0.029\right)$. MANOVA results indicated that there was neither a significant effect due to the $\mathrm{P}: \mathrm{C}$ ratio of the diet they were initially fed on (Pillai's trace $\left.=0.02012, F_{4,192}=0.49, P=0.745\right)$ nor a sex $\times$ diet interaction (Pillai's trace $=0.03888, F_{4,192}=0.95, P=0.4353$ ) for body composition measured on day 34 postecolsion.

\section{DISCUSSION}

We have previously shown that $T$. molitor beetles have the capacity to balance their intake of protein and carbohydrate by feeding on nutritionally complementary diets (Rho \& Lee, 2014). In the present study, we determined whether and how T. molitor beetles can recover from nutritional imbalances caused by ingesting diets that are deficient in one nutrient and contain an excess of another by compensatory food selection. To do so, we first subjected the experimental beetles to severe nutritional imbalances by feeding them diets that contained only protein or carbohydrate for 16 days during their early adulthood. Eating a food that is devoid of protein is likely to limit the ability of insects to repair existing proteins and to synthesize new ones while ingesting a food containing only protein is known to result in slow juvenile development, small body size and high mortality in many insects (Raubenheimer \& Simpson, 2003; Simpson et al., 2004; Lee, 2010). However, all beetles in our study survived the initial treatment, which indicates that $T$. molitor beetles are capable of tolerating extreme nutritional imbalances for a prolonged period in their early adult life. Physiological processes enabling T. molitor beetles to withstand such extreme nutritional imbalances remain to be addressed, but may be linked to their ability to feed on a variety of nutritionally extreme plant- and animal-derived materials (Ramos-Elorduy et al., 2002). For example, it is likely that insects alleviate the extreme carbohydrate shortage resulting from eating a protein-rich, carbohydrate-deficient food (p42:c0) by deaminating extra protein and using protein-derived carbon skeletons for energy (Thompson \& Redak, 2000; 
Wilkinson et al., 2001; Raubenheimer \& Simpson, 2003). Previous studies have shown that generalist-feeding insects, such as generalist herbivores and omnivores, tend to ingest a greater excess of protein than specialists because the former are more likely to utilize protein as an alternative source of carbohydrate than the latter (Lee et al., 2002, 2003; Simpson et al., 2002; Raubenheimer \& Simpson, 2003). Similarly, our data indicated that $T$. molitor beetles fed a protein-rich diet (p42:c0) ate more than those fed a carbohydrate-rich diet (p0:c42) during the no-choice period, perhaps indicating that these omnivorous scavengers are also capable of using protein-derived carbon in energy metabolism (Rho \& Lee, 2014).

Our results indicate that $T$. molitor beetles are capable of redressing a long-term nutritional imbalance by adjusting their food preferences. When allowed to select between two nutritionally complementary diets (p42:c0 and p0:c42), beetles initially fed one of the two nutritionally imbalanced diets $(\mathrm{p} 42: \mathrm{c} 0$ or $\mathrm{p} 0: \mathrm{c} 42)$ strongly preferred diets with the specific nutrient that was initially deficient in their diet. Male and female beetles that were fed on the optimal P : C diet (p21:c21) during the no-choice feeding period self-composed a slightly carbohydrate-biased ratio $(\mathrm{P}: \mathrm{C}=1: 1.23$ and $1: 1.61$ for males and females, respectively), which is close to the target intake ratio previously reported for this species (Ponton et al., 2010). Restoring a balanced nutritional state by complementary food selection is recorded for predatory beetles, cockroaches, grasshoppers and caterpillars that have experienced severe nutritional imbalances over a wide range of timescales (Simpson et al., 1988, 1990, 1991; Simmonds et al., 1992; Mayntz et al., 2005; Raubenheimer \& Jones, 2006; Lee et al., 2012), but we are not aware of any study on the ability of insects to redress the extreme nutritional imbalances accrued over 16 days. Specific foraging for deficient nutrients is likely to be controlled by blood-borne nutritional feedbacks that modulate the phagostimulatory responsiveness of peripheral taste receptors (Simpson et al., 1991; Simpson \& Raubenheimer, 1993). For example, when an insect is deprived of carbohydrate but satiated with protein, sugar levels in the blood fall while the concentrations of circulating free amino acids rise, causing the gustatory receptors to be more sensitive to carbohydrate and less sensitive to protein. Another possible mechanism facilitating nutrient rebalancing is learning (Simpson \& White, 1990).

An interesting aspect of our data is that the way in which beetles reinstated their nutritional balance by complementary food selection differed substantially depending on which specific nutrient was deficient in the pretreatment diet. Beetles initially fed on the synthetic diet containing only protein (p42:c0) strongly preferred the carbohydraterich diet during the first 6 days of food choice (days 16-22), but the extent to which this carbohydrate diet was preferred by them became less pronounced thereafter, with the pattern of food selection becoming closely similar to that of the control beetles that were initially fed the balanced diet (p21:c21) during the remainder of the food choice period (days 22-34). This indicates that self-selecting T. molitor beetles recovered from carbohydrate deficiency within 6 days by selecting the complementary diet. Similar compensatory feeding was recorded for beetles initially fed the protein-deficient diet ( $\mathrm{p} 0: \mathrm{c} 42$ ). As expected, these proteindeprived beetles strongly preferred the protein-rich diet during the first 6 days of food selection and this preference decreased as the food choice continued beyond day 6 . The cumulative protein-carbohydrate intake of the beetles initially fed on the protein-deficient diet (p0:c42) followed a trajectory with a shallower slope compared to that of those fed on the other initial diets and gradually converged to that of those initially fed on the balanced diet (p21:c21) during the course of the 18 days of choice feeding. By contrast, the cumulative macronutrient intake of the beetles that were initially deprived of carbohydrate (p42:c0) ran almost parallel to that of the control beetles (p21:c21). For carbohydrate-deprived beetles, the severe limitation in their source of energy experienced during the 16 days of the no-choice diet period is likely to be assuaged by using protein-derived carbon skeletons for energy metabolism (Raunbenheimer \& Simpson, 2003), thereby reducing the amount of carbohydrate that needs to be ingested for recouping the carbohydrate deficiency. In line with this prediction, we found that the behavioural compensation for carbohydrate-deficiency only lasted for the first 6 days of food choice. Since carbohydrate cannot substitute for protein, beetles initially fed on the protein-deficient diet (p0:c42) are expected to rely exclusively on the diet and hence may take longer to compensate for protein deficiency. The results presented in this study are largely consistent with the patterns of food preference previously recorded for Spodoptera litura caterpillars, which experienced extreme nutritional imbalances early in life (Lee et al., 2012).

The macronutrient balance of the pretreatment diet significantly influenced the body composition of beetles, but the composition of three pretreatment groups became statistically indistinguishable in nutrient space after 18 days of complementary food selection. This indicates that the effects of the nutritional imbalance on body composition were buffered by compensatory food mixing. A previous study on a predatory beetle (Agonum dorsale) indicates that the lipid content of self-selecting beetles increases rapidly from $14 \%$ to $46 \%$ over the first $48 \mathrm{~h}$ after emerging from winter diapause (Raubenheimer et al., 2007). In addition to complementary food selection, beetles might use a variety of post-ingestive regulatory mechanisms to cope with imbalanced nutrient intake, including the nutrientspecific modulation of the activity of digestive enzymes, physical restructuring of the alimentary canal and differential utilization of absorbed nutrients (Zanotto et al., 1994, 1997; Clissold et al., 2010; Raubenheimer \& Bassil, 2007). Despite having eaten significantly more protein than those initially fed on the balanced (p21:c21) and carbohydraterich, protein-deficient diets ( $0: \mathrm{c} 42)$, beetles that were initially fed on the protein-rich, carbohydrate-deficient diet (p42:c0) had a similar level of body protein content to those initially fed on the other diets, raising the possibility that these post-ingestive mechanisms for balancing 
their nutrient intake might have played an important role in regulating body protein content.

In conclusion, our results indicate that the beetle $T$. molitor is very capable of redressing the nutritional imbalance accrued over a long timescale by plastically adjusting their food consumption. Beetles fully compensated for their protein-deficiency by food selection and their potential ability to use protein as a source of both nitrogen and energy might have enabled them to overcome the state of carbohydrate-deficiency not only behaviourally but also physiologically. These results have implications for the nutrient balancing and foraging behaviour of this omnivorous beetle.

ACKNOWLEDGEMENTS. We thank an anonymous reviewer for comments that improved the earlier version of this manuscript. This research was supported by Seoul National University and Gokseong-Yeongwol Insect Industry Cluster Establishment Project, Republic of Korea.

\section{REFERENCES}

BeHmer S.T. 2009: Insect herbivore nutrient regulation. - Annu. Rev. Entomol. 54: 165-187.

Boersma M. \& Elser J.J. 2006: Too much of a good thing: on stoichiometrically balanced diets and maximial growth. Ecology 87: 1325-1330.

Clissold F.J., Tedder B.J., Conigrave A.D. \& Simpson S.J. 2010: The gastrointestinal tract as a nutrient balancing organ. Proc. R. Soc. Lond. (B) 277: 1751-1759.

Dussutour A. \& Simpson S.J. 2012: Ant workers die young and colonies collapse when fed a high-protein diet. - Proc. R. Soc. Lond. (B) 279: 2402-2408.

Fanson B.G., Fanson K.V. \& TaYlor P.W. 2012: Cost of reproduction in the Queensland fruit fly: Y-model versus lethal protein hypothesis. - Proc. R. Soc. Lond. (B) 279: 4893-4900.

Jensen K., Mayntz D., Tøғt S., Clissold F.J., Hunt J., RaubenHEIMER D. \& SiMPSON S.J. 2012: Optimal foraging for specific nutrients in predatory beetles. - Proc. R. Soc. Lond. (B) 279: 2212-2218.

LeE K.P. 2010: Sex-specific differences in nutrient regulation in a capital breeding caterpillar, Spodoptera litura (Fabricius). - J. Insect Physiol. 56: 1685-1695.

Lee K.P., Behmer S.T., Simpson S.J. \& Raubenheimer D. 2002: A geometric analysis of nutrient regulation in the generalist caterpillar Spodopetera littoralis (Boisduval). - J. Insect Physiol. 48: $655-665$.

Lee K.P., Raubenheimer D., Behmer S.T. \& Simpson S.J. 2003: A correlation between nutrient balancing and insect host-plant range: evidence from the specialist caterpillar Spodoptera exempta (Walker). — J. Insect Physiol. 49: 1161-1171.

Lee K.P., Simpson S.J., Clissold F.J., Brooks R., Ballard J.W.O., TALYOR P.W., Soran N. \& Raubenheimer D. 2008: Lifespan and reproduction in Drosophila: new insights from nutritional geometry. - Proc. Natl. Acad. Sci. USA 105: 2498-2503.

Lee K.P., Kwon S.T. \& RoH C. 2012: Caterpillars use developmental plasticity and diet choice to overcome the early life experience of nutritional imbalance. - Anim. Behav. 84: 785793.

LeE K.P., Kim J.S. \& Min K.J. 2013: Sexual dimorphism in nutrient intake and lifespan is mediated by mating in Drosophila melanogaster. - Anim. Behav. 86: 987-992.

Mattson W.J. 1980: Herbivory in relation to plant nitrogen content. - Annu. Rev. Ecol. Syst. 11: 119-161.
Mayntz D., Raubenheimer D., Salomon M., Tøғt S. \& Simpson S.J. 2005: Nutrient-specific foraging in invertebrate predators. - Science 307: 111-113.

Ponton F., Lalubin F., Fromont C., Wilson K., Behm C. \& Simpson S.J. 2011: Hosts use altered macronutrient intake to circumvent parasite-induced reduction in fecundity. - Int. J. Parasitol. 41: 43-50.

Ramos-Elorduy J., Avila González E., Rocha Hernández A. \& PINo J.M. 2002: Use of Tenebrio molitor (Coleoptera: Tenebrionidae) to recycle organic wastes and as feed for broiler chickens. - J. Econ. Entomol. 95: 214-220.

RAubenheimer D. \& BASSIL K. 2007: Separate effects of macronutrient concentration and balance on plastic gut responses in locusts. - J. Comp. Physiol. (B) 177: 849-855.

RAUBENHEIMER D. \& JoNES S.A. 2006: Nutritional imbalance in an extreme generalist omnivore: tolerance and recovery through complementary food selection. - Anim. Behav. 71: 12531262.

Raubenheimer D. \& Simpson S.J. 2003: Nutrient balancing in grasshoppers: behavioural and physiological correlates of dietary breadth. - J. Exp. Biol. 206: 1669-1681.

Raubenheimer D., Lee K.P. \& Simpson S.J. 2005: Does Bertrand's rule apply to macronutrients? - Proc. R. Soc. Lond. (B) 272: 2429-2434.

Raubenheimer D., Mayntz D., Simpson S.J. \& Tøғt S. 2007: Nutrient-specific compensation following diapause in a predator: implications for intraguild predation. - Ecology 88: 25982608.

RHo M.S. \& LeE K.P. 2014: Geometric analysis of nutrient balancing in a mealworm beetle, Tenebrio molitor L. (Coleoptera: Tenebrionidae). - J. Insect Physiol. 71: 37-45.

Roeder K.A. \& Behmer S.T. 2014: Lifetime consequences of food protein-carbohydrate content for an insect herbivore. Funct. Ecol. 28: 1135-1143.

SCHEINER S.M. 1993: MANOVA: Multiple response variables and multispecies interactions. In Scheiner M. \& Gurevitch J. (eds): Design and Analysis of Ecological Experiments. Chapman \& Hall, New York, pp. 94-112.

Simmonds M.S.J., Simpson S.J. \& Blaney W.M. 1992: Dietary selection behaviour in Spodoptera littoralis: the effects of conditioning diet and conditioning period on neural responsiveness and selection behaviour. - J. Exp. Biol. 162: 73-90.

Simpson S.J. 1982: Patterns in feeding: a behavioural analysis using Locusta migratoria nymphs. - Physiol. Entomol. 7: 325-336.

Simpson S.J. \& ABISGold J.D. 1985: Compensation by locusts for changes in dietary nutrients: behavioural mechanisms. Physiol. Entomol. 10: 443-452.

Simpson S.J. \& Raubenheimer D. 1993: The central role of the haemolymph in the regulation of nutrient intake in insects. Physiol. Entomol. 18: 395-403.

SimpSON S.J. \& RAUBENHEIMER D. 2012: The Nature of Nutrition: A Unifying Framework from Animal Adaptation to Human Obesity. Princeton University Press, Princeton, NJ, 229 pp.

Simpson S.J. \& White P. 1990: Associative learning and locust feeding: evidence for a 'learned hunger' for protein. — Anim. Behav. 40: 506-513.

Simpson S.J., Simmonds M.S.J. \& Blaney W.M. 1988: A comparison of dietary selection behaviour in larval Locusta migratoria and Spodoptera littoralis. - Physiol. Entomol. 13: 225-238.

Simpson S.J., Simmonds M.S.J., Blaney W.M. \& Jones J.P. 1990: Compensatory dietary selection occurs in larval Locusta migratoria but not Spodoptera littoralis after a single deficient meal during ad libitum feeding. - Physiol. Entomol. 15: 235-242. 
Simpson S.J., James S., Simmonds M.S.J. \& Blaney W.M. 1991: Variation in chemosensitivity and the control of dietary selection behavior in the locust. - Appetite 17: 141-154.

Simpson S.J., Raubenheimer D., Behmer S.T., Whitworth A. \& Wright G.A. 2002: A comparison of nutritional regulation in solitarious and gregarious phase nymphs of the desert locust, Schistocerca gregaria. - J. Exp. Biol. 205: 121-129.

Simpson S.J., Sibly R.M., Lee K.P., Behmer S.T. \& Raubenheimer D. 2004: Optimal foraging when regulation intake of multiple nutrients. - Anim. Behav. 68: 1299-1311.

THOMPSON S.N. \& REDAK R.A. 2000: Interactions of dietary protein and carbohydrate determine blood sugar level and regulate nutrient selection in the insect Manduca sexta L. - Biochim. Biophys. Acta 1523: 91-102.

WALDBAUER G.P. \& Friedman S. 1991: Self-selection of optimal diets by insects. - Annu. Rev. Entomol. 36: 43-63.
White T.C.R. 1993: The Inadequate Environment: Nitrogen and the Abundance of Animals. Springer, Berlin, $425 \mathrm{pp}$.

Wilkinson T.L., Minto L.B. \& Douglas A.E. 2001: Amino acids as respiratory substrates in aphids: an analysis of Aphis fabae reared on plants and diets. - Physiol. Entomol. 26: 225-228.

Zanotto F.P., Raubenheimer D. \& Simpson S.J. 1994: Selective egestion of lysine by locusts fed nutritionally unbalanced foods. - J. Insect Physiol. 40: 259-265.

Zanotto F.P., Gouveia S.M., Simpson S.J., Raubenheimer D. \& CALDER P.C. 1997: Nutritional homeostasis in locusts: Is there a mechanism for increased energy expenditure during carbohydrate overfeeding? - J. Exp. Biol. 200: 2437-2448.

ZeHNDER C.B. \& Hunter M.D. 2009: More is not necessarily better: the impact of limiting and excessive nutrients on herbivore population growth rates. - Ecol. Entomol. 34: 535-543.

Received August 20, 2014; revised and accepted November 18, 2014 Prepublished online January 22, 2015 